\title{
Assessment of coronary flow reserve by sestamibi imaging in patients with typical chest pain and normal coronary arteries
}

\author{
Giovanni Storto • Anna Rita Sorrentino • \\ Teresa Pellegrino • Raffaele Liuzzi • Mario Petretta • \\ Alberto Cuocolo
}

Published online: 22 July 2008

(C) Springer-Verlag 2008

\section{Erratum to: Eur J Nucl Med (2007) 34:1156-1161}

$$
10.1007 / \mathbf{s 0 0 2 5 9 - 0 0 6 - 0 3 3 3 - x}
$$

One of the affiliations was missing from the original publication. The full list of affiliations is given here.

G. Storto, A.R. Sorrentino, T. Pellegrino, R. Liuzzi, A. Cuocolo

Department of Biomorphological and Functional Sciences, Institute of Biostructures and Bioimages of the
National Council of Research, University Federico II, Naples, Italy

M. Petretta

Department of Internal Medicine, Cardiovascular and Immunological Sciences, University Federico II, Naples, Italy

T. Pellegrino, A. Cuocolo

SDN Foundation, Institute of Diagnostic and Nuclear Development, Naples, Italy

The online version of the original can be found at http://dx.doi.org/ 10.1007/s00259-006-0333-x.

G. Storto • A. R. Sorrentino - T. Pellegrino - R. Liuzzi •

A. Cuocolo $(\bowtie)$

Department of Biomorphological and Functional Sciences, Institute of Biostructures and Bioimages of the National Council of Research, University Federico II,

Naples, Italy

e-mail: cuocolo@unina.it

\section{Petretta}

Department of Internal Medicine, Cardiovascular and Immunological Sciences, University Federico II,

Naples, Italy

T. Pellegrino $\cdot$ A. Cuocolo

SDN Foundation, Institute of Diagnostic and Nuclear Development,

Naples, Italy 